distortions and compressions of the great veins as they approach the heart. Rotation of the trachea round a vertical axis and carrying forward of the right lung root, which are the result of the opening up of a retrotracheal pleural recess, have not apparently been recognized as changes likely to lead to the partial or complete occlusion of the lumen of the superior vena cava. The mechanism of the occlusion of the vena azygos major, as demonstrated

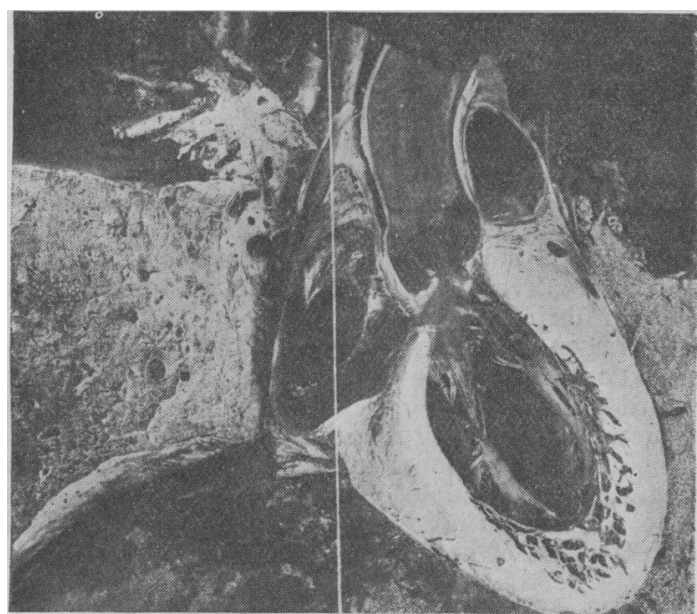

Fig. 3.- Coronal section through the heart on a plane $\frac{1}{3}$ in. anterior to the anterior lip of the inferior vens cavsl opening. rotation of. the ankex of the inferior vena cava, tbe downward photograph), and the bowing of the mediastinal structures. The white line is vertical, but on a plene a short distance to the right of the middle of the body of the last dorsal vertebra. It passes through the left margin of the inferior vena caval opening, round which point the rotation of the heart occurs. (See Fig. 4.)

in the dissection described above, is interesting, though possibly not of great clinical importance. The almost complete occlusion of the inferior vena cava resulting from the downward rotation of the apex of the heart

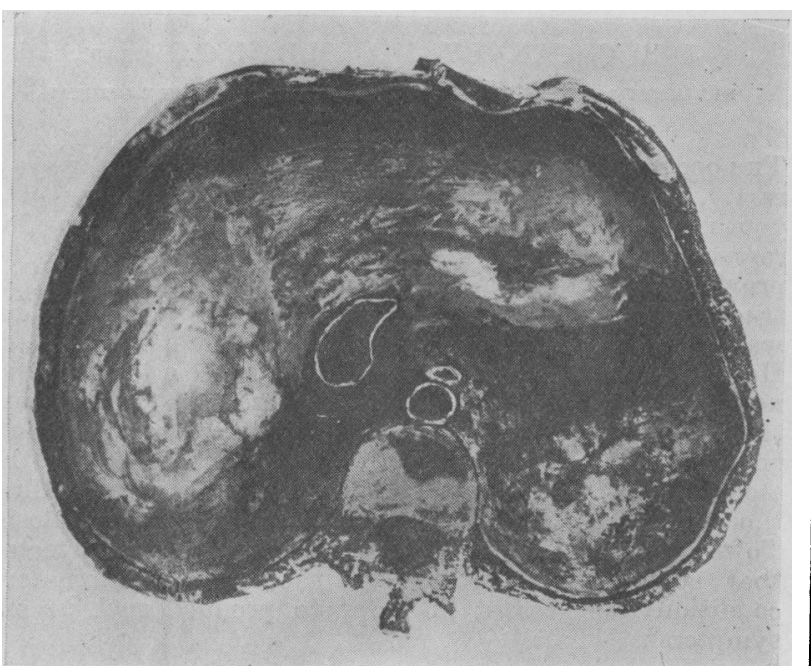

Fig. 4.-The inferior surface of the diaphragm. To show the flattening out of the right cupola and the depression of the cardiac orifice, which has been dragged out towards the left.

and the great diminution in the capacity of the right auricle under the influence of pressure are facts of clinical importance.

As a result of the consideration of the cases now and formerly described the present writer is confirmed in his opinion that one cause of sudden death in cases of right. sided pleural effusion may well be occlusion of the great veins as they approach the heart, and more especially occlusion of the inferior vena cava. This matter was referred to more fally in the short paper published on June 11th, 1910. The suggestion is not a new one, although it has not received general acceptance at the hands of the physicians.

A further point of interest is well brought out in Figs. 1 and 2, In these the descending thoracic aorta is seen to have been pushed clear of the left side of the vertebral bodies. This fact may provide a partial explanstion of the "area of dallness" which exists on the left side of the vertebral column in cases of right. sided pleural effusion.

My thenks are due to Mr. William Gill for the photographs from which the illustrations are taken and for assistance in the dissection.

REFEREnCE.
Elliot 8mith, On the Displacements produced by Pleural Eff usion, Iancet, Geptember 28th, 1907 .

\section{THE TREATMENT OF THREE HUNDRED NAEVI BY FREEZING.}

\section{By J. L. BUNCH, M.D., D.Sc.,} PHYSICIAN IN OHARGE OF THE SKIN DEPARTMENT, QUEEN'S HOSPITAL BRITISH MEDICAL ASSOCIATION.

Excellent as are some of the final results of treating naevi by means of radium, the method is, nevertheless, far from rapid and is beyond the means of many patients. For naevi in certain positions, such as those of the eyelids which involve the conjunctiva, radium has perhaps some advantages over other methods of treatment, and will still be used; but in the vast majority of cases equally good results can be obtained far more quickly, certainly. and cheaply by the application of solid carbon dioxide. Where the naevas is superficial a single application for a few seconds will effect a cure, and the resulting scar is so inconspicuous that it is diffioult even to detect. The great majority of the cases which I have treated have been, naturally, children, many of them only a few weeks old, and in such patients the painlessness and rapidity of any method of treatment is of great importance. The application is, of course, cold, and a tiny baby will probably cry, but I doubt if it feels any pain and older children will talk and laugh while they are heving several naevi, warts, or lupus nodules treated by this method. They say there is some feeling of burning or smarting while the tissues are thawing, but this very soon passes off. When a well marked, definitely raised and circumscribed angioma has to be treated, a single application is seldom sufficient, and I very mach prefer to do too little at the first application rather than too much, especially it the buccal mucous membrane or an eyelid is involved. But even if several applications are necessary, it must be remembered that the inconvenience to the patient is very slight, no anaesthetic is necessary, and no dressings beyond some boracic powder or boracic ointment are required. For naevi on the face there is no question that this method is far preferable to any surgical operation; for neevi on the trunk it might be said that excision was equally good and that the ecar does not matter; but I have seen a considerable number of such scars in which naevoid tissue has been left or has recurred, and where either a further excision or treatment by solid carbon dioxide was necessary.

I have successfully treated with carbon dioxide 300 naevi of varions extent and size. Most of these naevi were a source of disfgurement, many of them being on the face; but some of them were in positions where only a sentimental feeling on the part of the parents, and no cosmetic necessity, seemed to make their removal desirable. Such were Daevi of the valva, of the penis, and of the margin of the anus, and they were interesting from the point of view of the possibility of sepsis; but I have not seen one in these positions which gave any trouble or failed to react in the ordinary way or heal up pormally. Most of there cases were treated by me at the Queen's Hospital for Children, and included capillary, stellate, cavernous and pigmented naevi, some small and some several inches in diameter, flat, or markedly raised above the adjacent bealthy skin forming prominent red or purple swellings. For all such cases treatment by solid carbon dioxide cannot be im. proved upon, but for large port.wine stains, involving part or the whole of one side of the face, where a considerable area has to be treated at a single application, I prefer to employ liquid air. In the liquid state air occupies 1\% part of its ordinary volume; in other words, if liquid air be vaporized it will expand 800 times, and as the more 
volatile nitrogen evaporates the temperature rises and the almost colourless liquid assumes a bluish tinge-the colour of liquid oxygen-which remains until all the liquid has vaporized. Liquid air boils at $190^{\circ}$ C., so its use is especially adapted to those cases where a maximum rapidity of action is necessary, and the maximum degree of cold is required in the minimum time. For a port. wine stain or large capillary naevas an application of 5 to 7 seconds is sufficient, for cavernous neevi 8 to 10 seconds. Its mode of action is very similar to that of solid carbon dioxide.

Carbon dioxide has a critical temperature of $+31.30^{\circ} \mathrm{C}$., a boiling point of $-78.2^{\circ}$ C. when solid, and a melting point of $-56.2^{\circ} \mathrm{C}$. When solid it can be moulded into pencils or sticks of various sizes and shapes, so as accurately to fit any small naevas; thus a lesion no bigger than a pin's head can be frozen and removed with. out the slightest involvement of healthy skin. Naevi of the size of a five-shilling piece can also be treated with a single application, and any lesion between these two sizes, however irregular in shape. For larger lesions two or more applications, approximating but not overlapping, are necessary. The immediate effect of the application on the skin is to make it perfectly hard and white, depressed below the surrounding skin proportionstely to the amount of pressure which has been applied. This pressure must not, where soft parts underlie the angioma, be greater than that required to press the blood out of the superficial vessels, and the surface of the skin must be held as tense as possible during the application; where bone immediately underlies the lesion somewhat firmer pressure may be made, remembering that the depth frozen depends, other factors being the same, upon the amount of pressure applied. The daration of the application varies from twenty seconds for a superficial plexiform angioma to forty geconds for a cavernous angioma, while warts, which are bad conductors of cold, require as much as sixty seconds. The time required for thawing is rather longer than that for freezing; the skin then feels firmer, due to secondary hyperaemia and extravasation of serum, and within an hour or two a vesicle forms. Unless the application has been extremely short this vesicle does not become absorbed, and if not repestedly punctured with aseptic precautions and drained it becomes infected. If possible, therefore, the fluid should be evacuated aseptically each time the vesicle or balla fills up, and a pad of sterilized cotton-wool is under such circumstances all the dressing required. When, however, such draining of the bulla cannot be carried out efficiently, a dressing of zinc ointment dusted over with zinc and starch powder should be ordered and the patient told not to remove the impetiginous-like crust which forms, but let it come away of itself. This takes place in about ten days, and a deli. cate, smooth, and supple cicatrix forms, which is at first pink, bat later becomes paler and paler until it is almost invisible. The resulting scar may at first be slightly depressed below the surface of the surrounding skin, according to the nature of the lesion which has been treated and the extent of the freezing; but the scar is finally of the same tint as the healthy skin, equally soft, and practically inconspicuous.

In the case of cavernous and pigmented hairy naevi and raised localized angiomata excellent results are also obtained, but more than one application is usually neces. sary, and the scar, although fine in texture and supple, is more conspicuous in proportion to the depth and extent of the original lesion and the number of applications made.

I have also applied this method of treatment with success to lupus vulgaris, lupus -erythemstosus, warts, rodent ulcer, and old-standing patches of psoriasis and lichen planus. The duration of the application varies in the different cases, but the cutaneous reaction is similar to that already described in the case of naevi.

The histological changes in skin which has been frozen with carbon dioxide have been investigated by several observers, and more particularly by Juliusberg. If normal skin is frozen, and then immediately excised, sections of it show no pathological changes except thrombosis of the cutaneous vessels. If, however, normal skin is frozen hard for thirty seconds and excised fourteen hours after. wards, and hardened in 10 per cent. formalin solution sections show a similar thrombosis of the blood vessels, the thrombi being either hyaline or composed of leucocytes, erythrocytes, or both. Round the vessels is a well-marked infiltration of leucocytes. The lymphatics are dilated and filled with coagulated, homogeneous masses. Such sections show, however, the most marked changes in the epithelial layer, the cells of which appear structureless and homogeneous, and the nuclei are clear and, with the exception of some nuclei of the basal layer, do not stain. It is well known that at a temperature below $4^{\circ} \mathrm{C}$ water expands, and this expansion might, in the case of the epithelial cells, lead to ruptare of the cell membrane and the katabolic appearances seen in the sections. Beneath the epithelium is found a layer of large polynuclear leucocytes, which also infiltrate the connective tissue, while the connective tissue cells are swollen and hypertrophied. The elastic fibres are unchanged, but, if the section is strined with Weigert's fibrin stain, the whole connective tissue layer is found to be full of fine strands of fibrin.

It has been conclusively proved that neither liquid air nor solid carbon dioxide destroy the pathogenic properties nor inhibit the activity of micro-organisms, and this must be remembered when treating lupus and rodent ulcer.

Various forms of apparatus have been devised for the manufacture of suitable crayons or sticks of solid carbon dioxide, the essential being that the crayons shall be coherent, hard, of sufficient size, and readily moulded or cut to the desired shape. The necessary hardness-the crayon should sink when thrown into water-can be obtained by compressing the snow in a mould by a heavy rod cat to fit the mould, or by a plunger with a screw thread which is screwed down on to the soft snow until it is of the consistence of ice. With such an apparatus the solid carbon dioxide can be made nearly transparent, and the point of the cone moulded to any shape required.

\section{CARCINOMA OF THE STOMACH IN A YOUTH OF NINETEEN.}

BY

J. R. C. CANNEY, M.A., M.B., B.C.Cantab., RESIDENT MEDICAL OFFICER UNIVERSITY COLLEGE HOSPITAL. LONDON, w.C.

THE occurrence of carcinoma in young persons is always a rarity, and I therefore give a short report of a case of a youth of 19 in whom it was present. The growth in this instance was situated in the stomach, and, owing to its proving fatal while the patient was under observation, its true nature was investigated after death. The patient was treated on two occasions in University College Hospital, but a definite diagnosis, it must be admitted, was never made until after death. The reason for this was that, although the symptoms and signs were on the whole those usually associated with malignant disease of the stomach, owing to the patient's youth he was at first thought to be suffering from abdominal taberculosis. Towards the end of his illness, however, it was supected that something more serious than an inflammatory coudition was present in order to produce such urgent symptoms.

Clinical History.
J. J. D., just 19 years old, a french polisher by trade, came und. J., just 19 years old, a french polisher by trade, came under treatment on October 24th, 1909, for pain in the stomach, lasting eight weeks. The pain generally started half-way through a meal, and lasted for about three-quarters of an hour,
subsequently passing off. Until two days before he was first subsequently passing off. Until two days before he was first seen he had taken ordinary food, but since then had been on a milk diet, and had been to some extent relieved thereby. He had had bilious vomiting on one occasion only, but suffered much from flatulence. He had noticed something "like a bubble" pass across his stomach, the sensation lasting a few seconds.

It was interesting to find, on further questioning, that he gave a most accurate account of peristalsis, which had, gpparently, been visible sometimes.

The appetite was bad, and the bowels constipated. He was a teetotaler and a non-smoker, with no past or family history of importance.

He was wasted and anaemic, with a pulse of 96 and a temperature of $100^{\circ}$. Fxcept for a few moist sounds at the right base, there was nothing of importance in the chest. The abdomen showed slight distension, and on palpation had a generalized "doughy" feel, with no evidence of free or encapsuled fluid. In the epigastrium there was marked tender- 